\title{
HUBUNGAN PEMAKAIAN ALAT DAN OBAT KONTRASEPSI SUNTIKAN DENGAN GANGGUAN MENSTRUASI \\ DI KLINIK NIRMALA
}

\author{
Elvina Sari Sinaga*)
}

Surel: Elviansari@gmail.com

\begin{abstract}
According to the World Health Organization (WHO) there are nearly 380 million couples running Family planning. This research is a analttic survey with cross sectional design that is to know the relation of usage of contraception tool and contraception with menstrual disorder,sampling this research using accidental sampling that is sampling method by chance coincidence. In 85 out of 85 cases of mother using 1 month injection of polimenore/spooting injection were 50 cases (100\%) while mothers using 3 Months of injectable amenorrhea (65,71\%) had Spotted 12 case (34,29\%) ini clinic Nirmala. Result of statistical test by using chi square test got $p$ value $=0,01<0,05$ and $X^{2}=41,77$ mean there is relation of tool usage and contraceptive injection drug with menstrual disorder 95\% CI level equal to 1,84-4,61 meaning mothers who used injectable contraceptive devices 1-4 times experianced a menstrual disorder at the Nirmala Clinic
\end{abstract}

Keyword: Contraceptive Injection, Medication

PENDAHULUAN

\begin{tabular}{lcr}
\multicolumn{2}{c}{ Pelayanan } & kontrasepsi \\
merupakan & salah satu & komponen \\
dalam & pelayanan & Keluarga \\
Berencana & $(\mathrm{KB})$ & diharapkan \\
sebanyak-banyaknya pasangan usia \\
subur (PUS) & di Indonesia akan \\
mengikuti & gerakan Keluarga
\end{tabular}

Berencana (KB) secara dini dan
lestari semua jenis metode
kontrasepsi telah tersedia di seluruh
tempat pelayanan kesehatan dan
sangat mudah dijangkau oleh
masyarakat, kecuali metode,
kontrasepsi mantap yang
memerlukan tindakan operasi

(BkkbN, 2010).

*) Elvina Sari Sinaga, SST,. M.Biomed., Dosen STIKes Flora Medan 
Penggunaan kontrasepsi hormonal sebagai salah satu alat kontrasepsi meningkat tajam menurut World Health Organization (WHO). Dewasa ini hampir 380 juta pasangan menjalankan Keluarga Berencana dan 65-75 juta di antaranya terutama di Negara berkembang menggunakan kontrasepsi hormonal. Seperti kontrasepsi oral, suntik dan implant, kontrasepsi hormonal yang digunakan dapat memiliki pengaruh positif atau pun negatif terhadap berbagai organ wanita baik organ genetalia maupun non genetalia (Prawiroharjo, 2010).

Peserta Keluarga Berancana (KB) baru bulan agustus 2012 di Indonesia sudah mencapai 6.152.231 pengguna dengan pembagian sebagai berikut, 459.177 peserta IUD $(7,46 \%), \quad 87.079$ peserta MOW $(1,42 \%), \quad 17.331$ peserta MOP (0,28\%), 462.186 peserta Kondom (7,51\%), 527.569 peserta Implant $(8,58 \%)$, peserta Kontrasepsi Suntik (47,94\%), dan 1.649 .256 peserta Pil (26,81\%) (Rizal, 2013).

Dalam paradigma baru program Keluarga Berencana ini misalnya sangat menekankan pentingnya upaya menghormati hak-hak reproduksi sebagai upaya integral dalam meningkatkan kualitas keluarga dalam hal ini di jabarkan sebagai berikut memberdayakan masyarakat untuk membangun keluarga kecil bahagia dan berkualitas menggalangkan kemitraan dalam meningkatkan dan mewujudkan kesetaraan dan keadilan gender melalui program Keluarga Berencana dan mempersiapkan sumber daya manusia yang berkualitas sejak pembuahan dalam kandungan sampai dengan lanjut usia (BkkbN, 2011).

Berdasarkan hasil Survei Sosia Ekonomi Nasional (Susenas) tahun 2008, persentase wanita berumur 10 tahun ke atas pernah kawin dengan jumlah anak yang dilahirkan hidup terbesar adalah 0-2 orang $(49,72 \%)$ dan 3-5 orang $(35,83 \%)$ untuk daerah perkotaan dan pedesaan. Proporsi wanita 15-49 tahun yang berstatus kawin dan sedang memakai atau menggunakan alat $\mathrm{KB}$ menurut Susenas tahun 2008 sebesar 56,62\%, hal ini menunjukkan tidak mengalami perkembangan sejak tahun 2004 dan hingga tahun 2008 tidak jauh berbeda dengan tahun- 
tahun sebelumnya, pilihan alat kontrasepsi suntik dan pil $\mathrm{KB}$ masih terbanyak diminati oleh para wanita yang berstatus kawin dengan persentase $58,7 \%$ untuk kontrasepsi suntik dan 23,9\% untukpil KB (Depkes RI, 2009).

Berdasarkan hasil survey cakupan program $\mathrm{KB}$ di provinsi Lampung adalah jumlah sasaran PUS di provinsi lampung 115.657.3, sasaran PUS miskin 474.143, PUS dengan resiko 4 terlambat berjumlah 610.55, dan diperoleh cakupan dari sasaran PUS dengan factor resiko 4 terlambat berjumlah $32,85 \%$, dari data di atas dalam pemantaun persediaan alat kontrasepsi pengguna, KB suntik 266.908, dan diterima KB suntik 252.023,dan sisa yang didapatkan berjumlah $\mathrm{KB}$ suntik 183.94. Sedangkan 95\% lainnya tidak mengetahui tentang KB-MKJP (Dinas Kesehatan Provinsi Lampung Tahun 2012).

Peserta KB aktif di Sumatera Utara yang berhasil dibina sebanyak 2.326.172 pasangan $(64,64 \%)$, dari seluruh pasangan usia subur (PUS). Realisasi peserta KB aktif yang menggunakan kontrasepsi AKDR/IUD 153.627 peserta
(10,22\%), MOW 114.944 peserta (7,64\%), MOP 5.029 peserta (0,33\%), Kondom 91.691 peserta $(6,10 \%)$, Implant 133.741 peserta $(8,89 \%)$, Suntik 503.370 peserta $(3,48 \%)$, dan Pil 501.262 peserta $(33,34 \%)(B k k b N, 2013)$.

Survei awal yang dilakukan di Klinik Nirmala di Jln. Pasar 3 Krakatau priode 2013 dari data sekunder yang menggunakan kontrasepsi suntik berjumlah 3.000 akseptor, dengan $1.740 \quad(58 \%)$ akseptor menggunakan suntik cyclofem, dan 1.260 (42\%) akseptor menggunakan suntik Depo Medroksi Progesteron Asetat (DMPA). Dan dari data primer yang penelitilakukan di Klinik Nirmaladari 12 akseptor, yang hanya menggunakan suntik cyclofemada 5 akseptor, dan 3 akseptor mengalami gangguan spotting dan 1 akseptor tidak pernah mengalami keluhandan 1 akseptor mengalami polimenore, dandari 7 akseptor yang menggunakan Depo Medroksi Progesteron Asetat (DMPA), hanya 4 orang yang mengalami amenore, dan 3 akseptormengalami spotting. 
METODE PENELITIAN

Kerangka Konsep

\begin{tabular}{|c|}
$\begin{array}{c}\text { Kontrasepsi } \\
\text { Suntikan }\end{array} \longrightarrow \quad \begin{array}{c}\text { Gangguan } \\
\text { Menstruasi }\end{array}$ \\
\hline
\end{tabular}

Kontrasepsi suntikan adalah alat kontrasespsi berupa cairan yang berisi hormon progesteron yang disuntikan ke dalam tubuh wanita secara priodik.

Gangguan haid adalah perdarahan haid yang tidak normal dalam hal: panjang siklus haid, lama haid, dan jumlah darah haid. Melibatkan hipotalamus, hipofisis, ovarium danen drometrium

Jenis penelitian yang dilakukan adalah bersifat survey analitik dengan tipe explanatory research yaitu menjelasan hubungan pemakaian alat dan obat kontrasepsi suntikan dengan gangguan menstruasi. Dengan desain penelitian cross sectional yaitu untuk mengetahui hubungan pemakaian alat dan obat kontrasepsi suntikan dengan gangguan menstruasi di klinik Nirmala.

Penelitian ini dilakukan di Klinik Nirmala. Penelitian ini dilakukan di Klinik Nirmala.
Dimulai dari pengajuan judul, penelusuran kepustakaan, bimbingan proposal, persiapan proposal, seminar proposal, persiapan penelitian, pelaksanaan penelitian, analisis hasil penelitian, dan pengajuan hasil penelitian.

Populasi dalam penelitian ini adalah semua ibu yang dating kunjungan ulang KB suntikan cyclofem dan depomedroksi progesteronasetat (DMPA) sebanyak 85 kasus.

Teknik pengambilan sampel dalam penelitian ini menggunakan Accidantal Sampling yaitu cara pengambilan sampel dengan berdasarkan kebetulan bertemu sebanyak 85 kasus.

Pengumpulan data dalam penelitian ini menggunakan metode angket berupa data primer tentang hubungan pemakaian alat dan obat kontrasepsi suntikan dengan gangguan menstruasi dengan cara memberikan angket kepada responden di Klinik Nirmala.

Penelitian menggunakan lembar angket sebagai instrument dalam pengumpulan data. Lembar angket berjumlah 1 soal jenis 
kontrasepsi suntikan, 1 soal jenis lama menggunakan kontrasepsi suntikan, dan 1 soal dengan gangguan menstruasi.

$$
\text { Pengukuran dalam }
$$

penelitian ini dimaksudkan untuk

\begin{tabular}{|c|c|c|c|}
\hline Vvariabel & $\begin{array}{l}\text { Definisi } \\
\text { Operasional }\end{array}$ & Kategori & Skala \\
\hline $\begin{array}{l}\text { Akseptor } \\
\text { Suntikan }\end{array}$ & $\begin{array}{l}\text { Alat kontrasepsi berupa cairan } \\
\text { berisi hormon Estrogen dan Progesteron } \\
\text { yang disuntikan ke dalam tubuh } \\
\text { wanita secara priodik. }\end{array}$ & $\begin{array}{l}0: 1 \mathrm{~B} \ln \\
1: 3 \mathrm{~B} \ln \end{array}$ & Nominal \\
\hline $\begin{array}{l}\text { Gangguan } \\
\text { Menstrua } \\
\text { si }\end{array}$ & $\begin{array}{l}\text { Perdarahan haid yang tidak normal dalam hal } \\
\text { panjang siklus haid,lama haid dan jumlah darah }\end{array}$ & $\begin{array}{c}0 \text { :Tidak menstruasi } \\
\text { (Amenorea) } \\
\text { 1:Menstruasi(Polime } \\
\text { norea,Spotting) }\end{array}$ & Nominal \\
\hline
\end{tabular}

Data yang akan dikumpulkan sebelumnya dilakukan dengan menggunakan langkah-langkah sebagai berikut :

Editing

Data diperiksa satu persatu dari wawacara dan metode angket, dalam penelitian ini data terkumpul dengan lengkap dan tidak ada kesalahan atau kekurangan.

Coding

$$
\text { Jawaban diklasifikasikan }
$$
menurut macamnya dengan memberikan tanda kode checklist $(\sqrt{ })$ untuk mempermudah perhitungan data. menentukan indicator dari variabel yang telah di tentukan sebagai berikut :

\section{Tabulating}

Setelah data diberi kode, kemudian dikumpulkan sesuai dengan variabel yang diteliti dengan menggunakan metode format checklist lalu dimasukan kedalam tabel distribusi frekuensi.

\section{Analisis Data}

Data yang dilakukan dalam penelitian ini adalah berupa data yang berskala nominal sesuai dengan tujuan penelitian, maka analisa dilakukan dengan dua cara yaitu :
Analisis Univariat 
Analisa univariat dilakukan (kontrasepsi suntikan) dan variabel untuk mendapatkan gambaran dependen (gangguan menstruasi) dan karakteristik masing-masing variabel dilakukan uji statistik dengan yaitu, variabel independen melakukan uji chi square. Untuk (kontrasepsi suntikan) dan variabel hipotesis yang digunakan adalah uji dependen (gangguan menstruasi). chi square pada taraf kemaknaan $\alpha=$ 0,05 (derajat kepercayaan 95\%). Bila

Analisis Bivariat $\rho<0,05$, maka hasil statistik

Analisa bivariat dilakukan untuk dikatakan ada hubungsan secara mendapatkan hubungan antara bermakna.

variabel yaitu, variabel independen

\section{HASIL PENELITIAN DAN PEMBAHASAN}

\section{Distribusi Frekuensi Kontrasepsi Suntikan Di Klinik Nirmala}

\begin{tabular}{llll}
\hline No & Kontrasepsi Suntikan & Frekuensi & $\%$ \\
\hline 1 & 1 bulan & 50 & 58,8 \\
2 & 3 bulan & 35 & 41,2 \\
& Jumlah & 85 & 100 \\
\hline
\end{tabular}

Berdasarkan tabel 4.1 ditemukan dari 85 kasus mayoritas ibu yang menggunakan suntikan 1 bulan sebanyak 50 kasus $(58,8 \%)$ dan minoritas yang mengunakan suntikan 3 bulan Sebanyak 35 kasus (41,2\%).

\section{Distribusi Frekuensi Gangguan Menstruasi Di Klinik Nirmala}

\begin{tabular}{llll}
\hline No & Gangguan Menstruasi & Frekuensi & $\%$ \\
\hline 1 & Amenore & 23 & 27,1 \\
2 & Polimenore/spotting & 62 & 72,9 \\
& Jumlah & 85 & 100 \\
\hline
\end{tabular}


Berdasarkan tabel 4.2 ditemukan dari 85 kasus mayoritas yang mengalami polimenore/spotting sebanyak 62 kasus (72,9\%) dan minoritas mengalami amenore sebanyak 23 kasus $(27,1 \%)$.

Tabel 4.3

Distribusi Frekuensi Kontrasepsi Suntikan Dengan Gangguan Menstruasi Di Klinik Nirmala

\begin{tabular}{|c|c|c|c|c|c|c|c|c|c|c|c|}
\hline \multirow[t]{3}{*}{ No } & \multirow{3}{*}{$\begin{array}{l}\text { Kontrasepsi } \\
\text { Suntikan }\end{array}$} & \multicolumn{4}{|c|}{ Gangguan Menstruasi } & \multirow{2}{*}{\multicolumn{2}{|c|}{ Jumlah }} & \multirow[t]{2}{*}{$P($ sig $)$} & \multirow[t]{2}{*}{$\mathbf{X}^{2}$} & \multicolumn{2}{|c|}{$95 \% \mathrm{CI}$} \\
\hline & & \multicolumn{2}{|c|}{ Amenore } & \multicolumn{2}{|c|}{$\begin{array}{l}\text { Polimenore } \\
\text { spotting }\end{array}$} & & & & & $\mathbf{L}$ & $\mathbf{U}$ \\
\hline & & f & $\%$ & $\mathbf{F}$ & $\%$ & f & $\%$ & \multirow{3}{*}{0,01} & \multirow{3}{*}{41,77} & \multirow{3}{*}{1,84} & \multirow{3}{*}{4,61} \\
\hline 1 & 1 bulan & - & - & 50 & 100 & 50 & 100 & & & & \\
\hline 2 & 3 bulan & 23 & 65,71 & 12 & 34,29 & 35 & 100 & & & & \\
\hline
\end{tabular}

Berdasarkan tabel 4.3 menunjukkan bahwa dari 85 kasus ibu yang menggunakan kontrasepsi suntikan 1 bulan yang mengalami polimenore/spotting sebanyak 50 kasus (100\%) sedangkan ibu yang menggunakan kontrasepsi suntikan 3 bulan yang mengalami amenore sebanyak 23 kasus $(65,71 \%)$ dan yang mengalami spotting sebanyak 12 kasus $(34,29 \%)$.

Nirmala.

Berdasarkan tabel 4.3 menunjukkan bahwa dari 85 kasus ibu yang menggunakan kontrasepsi suntikan 1 bulan yang mengalami
Hasil uji statistik dengan menggunakan uji chi square didapat nilai $p=0,01<0,05$ dan $X^{2}=41,77$ berarti ada hubungan pemakaian alat dan obat kontrasepsi suntikan dengan gangguan menstruasi pada taraf $95 \%$ CIsebesar 1,84-4,61, artinya ibu yang menggunakan alat kontrasepsi suntikan sebesar 1-4 kali mengalami gangguan menstruasi di Klinik polimenore/spotting sebanyak 50 kasus (100\%) sedangkan ibu yang menggunakan kontrasepsi suntikan 3 bulan yang mengalami amenore sebanyak 23 kasus $(65,71 \%)$ dan 
yang mengalami spotting sebanyak 12 kasus $(34,29 \%)$.

Hasil uji statistik dengan menggunakan uji chi square didapat CI sebesar 1,84-4,61, artinya ibu yang menggunakan alat kontrasepsi suntikan sebesar 1-4 kali mengalami gangguan menstruasi di Klinik Nirmala.

Berdasarkan hasil penelitian Veronika (2010), menunjukkan bahwa nilai $\mathrm{p} 0,01$, sehingga nilai $\mathrm{p}$ $0,01<0,05$, sehingga dapat di simpulkan Ho ditolak. Sehingga dapat di simpulkan ada hubungan pemakaian alat dan obat kontrasepsi suntikan dengan gangguan menstruasi, dengan kejadian seperti amenorea dan polimenore pada akseptor KB suntik. Disimpulkan bahwa semakin lama menggunakan Depo Medroxy Progesterone Acetat (DMPA), maka semakin tinggi kejadian amenorea sekunder pada akseptor KB suntik. Untuk mengetahui seberapa besar tingkat hubungan antara lama penggunaan Depo Medroxy Progesterone Acetat (DMPA) dengan kejadian amenorea sekunder pada akseptor KB suntik menunjuk pada nilai kontingensi sebesar 0,258. Nilai kontingensi nilai $\mathrm{p}=0,01<0,05$ dan $\mathrm{X} 2=41,77$ berarti ada hubungan pemakaian alat dan obat kontrasepsi suntikan dengan gangguan menstruasi pada taraf $95 \%$ diinterpretasikan pada koefisiensi kontingensi bahwa lama penggunaan Depo Medroxy Progesterone Acetat (DMPA) terhadap kejadian amenorea sekunder adalah rendah.

Berdasarkan hasil penelitian Dewi Murdiyanti (2006), hasil uji statistik mengenai hubungan pemakaian alat dan obat kontrasepsi suntikan dengan gangguan menstruasi di dapat hasil uji sperman rank di peroleh hasil nilai rho hitung adalah 0,583 dengan $\mathrm{p}$ 0,001 pada taraf signifikan $(\alpha) 5 \%$. Karena p 0,001 < $\alpha$, maka H0 ditolak dan Ha di terima yang berarti ada hubungan pemakaian alat dan obat kontrasepsi suntikan dengan gangguan menstruasi di BPS Sumarni, Pundong Bantul, Yogyakarta.

Hasil penelitian ini sejalan dengan Veronika (2010) dan Dewi Murdiyanti (2006) dimana menunjukkan bahwa nilai p 0,01 < 0,05, sehingga dapat disimpulkan bahwa ada hubungan pemakaian alat dan obat kontrasepsi suntikan dengan 
gangguan menstruasi. Hal ini menunjukkan bahwa banyak akseptor yang telah menggunakan alat kontrasepsi suntikan karena terdapat banyak keuntungan dari kontrasepsi lainnya, dibandingkan dengan jenis alat kontrasepsi yang lain. Keuntungan dalam menggunakan kontrasepsi suntikan yaitu dapat mencegah kehamilan jangka panjang, tidak mempengaruhi hubungan suami istri, tidak perlu periksa dalam, angka kegagalan rendah, dan sedikit efek samping. Sedangkan kerugian dari kontrasepsi suntikan adalah sering ditemukan gangguan haid seperti siklus haid memendek atau memanjang, perdarahan yang banyak atau sedikit, perdarahan tidak teratur atau bercak (spotting), bahkan tidak haid sama sekali (amenorea).

\section{SIMPULAN}

Bahwa dari 85 kasus ibu yang menggunakan kontrasepsi suntikan 1 bulan yang mengalami polimenore atau spotting sebanyak 50 kasus (100\%) sedangkan ibu yang menggunakan kontrasepsi suntikan 3 bulan yang mengalami amenore sebanyak 23 kasus $(65,71 \%)$ dan yang mengalami spotting sebanyak 12 kasus $(34,29 \%)$.

Hasil uji statistik dengan menggunakan uji chi square didapat nilai $\rho=0,01<0,05$ dan $\mathrm{X} 2=41,77$ berarti ada hubungan pemakaian alat dan obat kontrasepsi suntikan dengan gangguan menstruasi pada taraf $95 \%$ CI sebesar 1,84-4,61, artinya ibu yang menggunakan alat kontrasepsi suntikan sebesar 1-4 kali mengalami gangguan menstruasi di Klinik Nirmala.

\section{Saran}

1. Bagi Klinik Nirmala Medan diharapkan untuk selalu meningkatkan pelayanan dan selalu memberikan informasi tentang kontrasepsi suntikan khususnya dengan gangguan menstruasi.

2. Bagi STIKes Widya Husada Medan diharapkan hasil penelitian ini dapat di pergunakan sebagai bahan referensi untuk penelitian selanjutnya.

\section{DAFTAR PUSTAKA}

Affandi, Bidar, Dkk. 2006. Buku Panduan Praktis Pelayanan Kontrasepsi. 
Yayasan Bian Pustaka

Sarwono Prawihardjo:

Jakarta.

Giam dan The. 2002. Ilmu

Kedokteran Olahraga.

Binapura Aksara: Jakarta.

Irianto, Koes,. 2012. Keluarga

Berencana untuk

Paramedis \& Nonmedis.

Yrama Widya: Bandung.

Meilani, Niken, Dkk,. 2010.

Pelayanan Keluarga

Berencana. Fitramaya:

Yogyakarta.

Prawiharjo, Sarwono,. 2007. Ilmu

Kebidanan. Yayasan Bina

Pustaka Sarwono

Prawiharjo: Jakarta.

Riwidikdo H. 2009. Statistik Untuk

Penelitian Kesehatan

Dengan Aplikasi Program

$R$ dan SPSS: Yogyakarta.

Saifuddin AB. 2006. Buku Panduan

Praktis Pelayanan

Kontraspsi: Jakarta.

Sugiyono. 2009. Metode Penelitian

Pendidikan: Bandung.

Siswosudarmo, HR, Dkk,. 2007.

Teknologo Kontrasepsi.

Gadjah Mada University

Press: Yogyakarta.
Veronika. 2010. Hubungan Pemakaian Alat Dan Obat Kontrasepsi Suntikan Dengan Gangguan Menstruasi. Saleman: Bandung.

Wilopo, SA,. 2008. Rekomendasi Praktek Terpilih Untuk Penggunaan Kontrasepsi. Universitas Gadjah Mada: Yogyakarta. 